\title{
Evolution of Anisotropy in Hierarchical Porous Ceramics During Sinter-Forging
}

Haixia Shang ${ }^{1}$, Aravind Mohanram ${ }^{2}$, Eugene Olevsky ${ }^{3}$ and Rajendra K. Bordia ${ }^{1,4^{*}}$

${ }^{1}$ Department of Materials Science and Engineering, Roberts Hall, Box 352120 University of Washington, Seattle, WA 98195 USA

${ }^{2}$ Saint-Gobain Northborough Research and Development Center

${ }^{3}$ Department of Mechanical Engineering, San Diego State University, San Diego, CA 92182

${ }^{4}$ Current Address: Department of Materials Science and Engineering, 161 Sirrine Hall, Clemson University, Clemson, SC 29634 USA

* Corresponding Author

rbordia@clemson.edu, 1-864-656-5228

Haixia.shang@gmail.com, 1-206-685-7216

Aravind.Mohanram@saint-gobain.com, 1-508-351-7600

eolevsky@mail.sdsu.edu

C 2015. This manuscript version is made available under the Elsevier user license http://www.elsevier.com/open-access/userlicense/1.0/ 


\begin{abstract}
When a body is sintered under non-hydrostatic stress (or strain) fields, anisotropic microstructures may develop which would have an impact on the performance of sintered products. In this study, we focus on the development of pore shape anisotropy during sintering forging. Several parameters were used to characterize the anisotropy of both intrinsic (small inter-particle pores) and extrinsic (large pores from the burnout of poreformers). The effect of applied stress on grain growth was also investigated. As expected during sinter forging, the pore shape becomes anisotropic and the pores orient preferentially. The intrinsic pores preferentially align parallel while the extrinsic pores align perpendicular to the applied stress. For both intrinsic and extrinsic pores, the degree of anisotropy increases with applied stress, reaches a maximum and then decreases with further increase in stress. Applied stress leads to finer grain microstructures at a particular density. Possible explanations are proposed to explain these observations.
\end{abstract}

Key words: Anisotropy, grain growth, densification, sinter forging, porous ceramics_. 


\section{INTROPUCTION Introduction}

Hierarchically porous ceramics are used in a variety of well-established and emerging applications, such as energy conversion and storage, metal filtration, gas separation membranes, catalysis, and refractory insulation. For many applications, the hierarchical microstructures have enhanced properties compared with single pore size porous materials due to the ability to optimize both properties that require large pore size (e.g. gas and liquid transport) and those that require small pore size (e.g. surface chemical reactions) [1]. In some of these applications, the ceramic is processed under an applied stress or in a constrained geometry (e.g. sintering of multilayered ceramics or sintering of coatings on substrates). In these approaches, either a non-isotropic stress or non-isotropic strain field is imposed on the sintering bodies. The densification under these conditions has been extensively studied (e.g. [2-8]). A continuum theory of sintering has been developed to predict sintering under these conditions with contribution by several research groups and has been periodically reviewed [9-14] Experimentally, for porous ceramics with only intrinsic pores, the application of external stresses during sintering and constrained sintering has been shown to lead to an anisotropic microstructures especially in the final stage of sintering [15-20]. It has been suggested that the nonuniform strain/ stress can cause directional diffusional fluxes in sintering body and lead to elongated pores. However, the evolution of such anisotropy during the entire sintering cycle has not been well documented and is one of the focal areas of this study.

Both continuum and multi-scale approaches have been developed to analyze and simulate the anisotropic microstructures [21-24]. In Ref. 25, the formal equivalence between the two important experimental situations that lead to transversely isotropic microstructures, 
viz. sinter-forging and constrained sintering, was established. However, the predictions and fidelity of these approaches have not been rigorously tested.

It should also be noted that the size dependence of the pore shrinkage kinetics has been reported for free sintering and isostatic pressing of various materials [26-32]. For nonisostatic pressure-assisted sintering processes the relationship between the pore sizes and their evolution should be associated not only with the change of their volume, but also with their shape. This fact renders the possibility of the pore texture/pore orientationbased structure anisotropy imposed by sinter forging. The size dependence of this kind of anisotropy has not been previously studied and is another focal area of this investigation.

Thus, the purpose of this work was to investigate the evolution of anisotropy for porous materials, with both intrinsic and extrinsic pores, during pressure-assisted sintering. Sinter forging was performed on porous ceramics with bimodal starting pore size distribution at different sintering temperatures and stress levels. The evolution of anisotropic pore geometry and the key properties that affect the formation of the anisotropic porous microstructures were investigated. The analysis of these effects is of significant importance for programmable processing of ceramic materials enabling the possibility of final product structure optimization and predictable sintering outcomes.

\section{EXPERIMENTAL PROCEDURES Experimental Procedures}

The experimental studies were conducted on a standard cathode composition for a solid oxide fuel cell. The porous cathodes were of the standard cathode composition and prepared by mixing $40 \mathrm{vol} \% \mathrm{LSM}\left(\mathrm{La}_{0.8} \mathrm{Sr}_{0.2} \mathrm{MnO}_{3}\right)$ with $60 \mathrm{vol} \%$ of $8 \mathrm{~mol} \% \mathrm{YSZ}$ (Yitria stabilized zirconia) [33]. The LSM powder used was LSM20 (NexTech 
Materials, Lewis Center, OH, USA $d_{50}=1.10 \mu \mathrm{m}$ ) and the YSZ had a $d_{50}=0.32 \mu \mathrm{m}$ (Tosoh USA Inc., Grove City, OH, USA). PMMA polymer particles with a $d_{50}$ of 7.50 $\mu \mathrm{m}$ (Arkema, Cary, NC, USA) were used to generate extrinsic pores. The weighted powders (the amount of PMMA used is based on volume fraction in the fully dense composite cathode) for the desired compositions were wet ball milled and dried on a hot plate at temperature of $100^{\circ} \mathrm{C} 373 \mathrm{~K}$. Cylindrical samples (diameter $12.75 \mathrm{~mm}$ and height $12 \mathrm{~mm}$ ) were made by uniaxial pressing the crushed dried powders at a uniaxial stress of $200 \mathrm{MPa}$.

The sinter forging experiments were performed in a MTS loading frame (MTS Systems Cooperation, MN, USA) equipped with a high temperature furnace (temperature ranging from $20^{\theta} \mathrm{C} 293$ to $1600^{\circ} \mathrm{C} 1873 \mathrm{~K}$ ). Uniaxial compression tests were performed in air from $1200^{\circ} \mathrm{C} 1473$ to $1300^{\circ} \mathrm{C}-1573 \mathrm{~K}$ with stresses in range of 0 to $12 \mathrm{MPa}$. Sapphire disks were used to avoid direct contact between the specimen and SiC push rods. The temperature was increased from room temperature to $40 \theta^{\theta} \mathrm{C} 673 \mathrm{~K}$ at a heating rate of 10 $\mathrm{K} / \mathrm{min}$, held at $4 \mathrm{f}^{0} \mathrm{E}-673 \mathrm{~K}$ for 30 minutes to burn out the binder and pore former (if any), and then increased to the final temperatures at $10 \mathrm{~K} / \mathrm{min}$ followed by 90 minute isothermal hold. The samples were then cooled to room temperature at $10 \mathrm{~K} / \mathrm{min}$. The compressive stress was applied when the temperature was $50 \mathrm{~K}$ lower than $\mathrm{T}_{\max }$ and released at the end of the isothermal hold. The compressive stress was applied when sample temperature was $50^{-\oplus} \mathrm{C}$ less than and the stress was released at the end of the isothermal hold. The relative density of a sintered specimen was measured by Archimedes method and averaged for three samples processed under identical conditions. 
For microstructure observation, the sintered specimens were cut in two cross-sections parallel and perpendicular to the loading direction, through the center of specimens, and polished down to $1 \mu \mathrm{m}$ diamond finish. The microstructure was examined on the polished surfaces using scanning electron microscope (JSM 7000, JEOL-USA, Inc., Peabody, MA). Pore size and morphology and grain size were determined, after image processing, using image analysis (NIH Image J National Institutes of Health, Bethesda, MD, USA). The average grain size of sintered body was calculated using the linear intercept method with a conversion factor of 1.56 [34] for approximately 200 grains per sample. Note grain size measurement is complicated by a number of factors, such as 3-dimensional size of the grain is not constant, grain shape varies, and grain shapes can be distorted by processing procedures. However, in most cases, the grains observed on a polished crosssectional plane exhibit a range of sizes around a central mean and individual measurements of intercept lengths (or grain areas) exhibit a normal distribution, thus the mean value of the grain size is representative.

\section{PARAMETERS TO-QUANTIFY ANISOTROPY OF PORES-Microscrutural}

\section{parameters to quantify anisotropy of pores}

Evolution of intrinsic and extrinsic pores during sinter forging was investigated separately. Intrinsic pores are those created due to particle packing in the green stage. They exist in the powder compacts and their size is of the order of the particle size. Extrinsic pores are pores formed from the burn out of fugitive particles (e.g. polymeric pore formers), large voids between agglomerates or formed due to evolved gases. The extrinsic pore size is much larger than the average particle diameter. Microstructures of sintered samples in our experiments have shown that extrinsic pores have pore size larger 
than $2 \mu \mathrm{m}$, and all intrinsic pores size is less than $2 \mu \mathrm{m}$. Therefore $2 \mu \mathrm{m}$ was used as a threshold value to differentiate intrinsic and extrinsic pores in image processing and subsequent analysis.

Based on the microstructure analysis following from Ref. 20, four parameters, average pore angle $\boldsymbol{\theta}$, average pore elongation factor $\varepsilon$, average pore size $d m$, and pore orientation index $k$ have been used to quantify the anisotropy of pores. Assuming each pore as an ellipsoid with three axes- major axe $d_{i}{ }^{m a j}$, minor axe $d_{i}{ }^{m i n}$, and $\left(d_{i}{ }^{m a j}+d_{i}\right.$ $\left.{ }^{\mathrm{min}}\right) / 2$, the four parameters are defined as follows: average pore angle $\theta$ is an arithmetic mean of the pore angle $\theta i$ (angle between the $d_{i}{ }^{m a j}$ and $x$-axis (x-axis is perpendicular to the loading direction)). Note the angles from $90-180^{\circ}$ are mirrored across the loading direction. Average pore elongation factor $\varepsilon$ is defined as the arithmetic mean of the aspect ratio of the pores $\left(\varepsilon_{i}=d_{i}{ }^{m a j} / d_{i}{ }^{m i n}\right)$ weighted by pore volume [20]:

$$
\varepsilon=\frac{\sum_{i} \varepsilon_{i} d_{i}^{\min }\left(d_{i}{ }^{m a j}+d_{i}^{\mathrm{min}}\right) d_{i}{ }^{m a j}}{\sum_{i} d_{i}^{\min }\left(d_{i}{ }^{m a j}+d_{i}^{\mathrm{min}}\right) d_{i}{ }^{m a j}}
$$

The average pore size was calculated by the arithmetic mean of $\left(d_{i}{ }^{m a j}+d_{i}{ }^{m i n}\right) / 2$ weighted by pore volume and multiplied by the conversion factor $4 / \pi$, considering observed surface could be cut from any position of an ellipsoid in a 2-D image.

$$
d_{m}=\frac{4}{\pi} \frac{\sum_{i} d_{i}{ }^{\mathrm{min}}\left(d_{i}^{{ }^{m a j}}+d_{i}^{\mathrm{min}}\right)^{2} d_{i}^{{ }^{m a j}} / 2}{\sum_{i} d_{i}^{\mathrm{min}}\left(d_{i}^{\mathrm{maj}}+d_{i}^{\mathrm{min}}\right) d_{i}^{\text {maj }}}
$$

and the pore orientation $k$ was quantified by using the angle $\theta i$ [20]: 


$$
k=\ln \left(\frac{\sum_{i}\left(\varepsilon_{i} d_{i}^{m a j} \sin \theta_{i}\right)^{2}}{\sum_{i}\left(\varepsilon_{i} d_{i}^{m a j} \cos \theta_{i}\right)^{2}}\right)
$$

The logarithm is used to introduce a difference between vertically and horizontally aligned pores. If $k=0$, there is no preferential orientation of the pores. When $k>0$, the pores are preferentially oriented perpendicular to the loading direction, and when $k<0$ the pores are preferentially oriented parallel to the loading direction. Each parameter was calculated and averaged from 400-600 pores in corresponding SEM pictures.

\section{EXPERIMENTAL RESULTS EXPERIMENTAL RESULTS Experimental}

\section{Results}

\subsection{Densification during sinter-forging}

The effect of uniaxial stress and temperature on porosity of composite cathodes with 0 and 30 vol\% PMMA is shown in Figure 1.

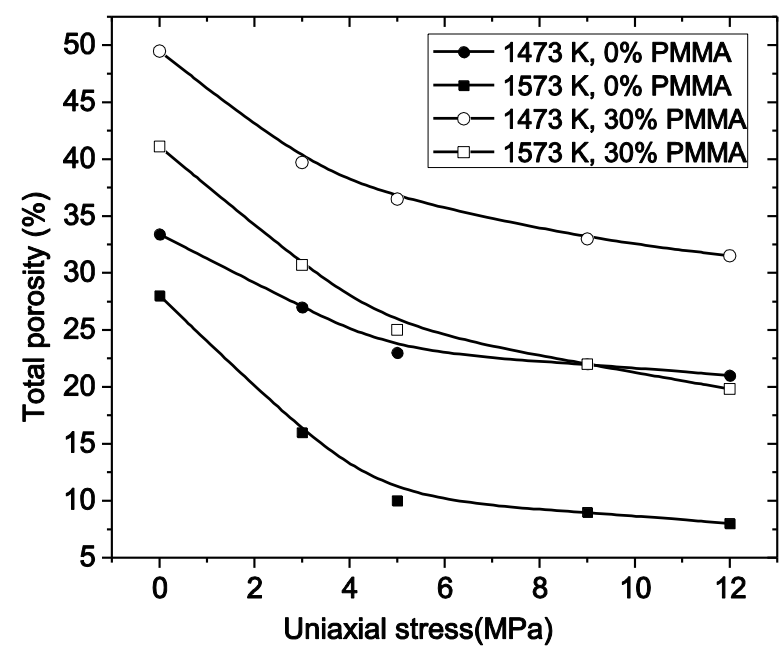

Fig. 1: Effect of temperature and uniaxial stress on the porosity of samples with/without PMMA. The samples were held at the temperature for 90 minutes 
As expected, porosity decreases with increasing temperature and pressure uniaxial compressive stress. but it decreases faster in the lower pressure range $(0-5 \mathrm{MPa})$ compared to the higher pressure $(5-12 \mathrm{MPa})$. The effect of increasing stress is higher in the lower stress regime (0 to $5 \mathrm{MPa}$ ) compared to the higher stress regime (5 to $12 \mathrm{MPa}$ ). This may be due to the fact that once the matrix of composite cathode achieves certain density further increase in pressure will not significantly influence the porosity of sample. Introducing 30 vol\% PMMA into the cathode can produce about 15 vol\% more porosity in sintered samples. This is clear evidence that large extrinsic pores also shrink during sintering as has been reported previously $[31,32,35,36]$. For sample without pore former, the porosity is due to intrinsic pores while for sample with 30\% PMMA, both intrinsic and extrinsic pores contribute to the total porosity.

\subsection{Pore orientation of intrinsic and extrinsic pores}

Our study indicates that in the plane perpendicular to the loading direction (Figure 2, cross-section B), no anisotropy developed in the shape of the intrinsic and extrinsic pores, although some samples accompanied expansion in radical directions. However, in the plane parallel to the loading direction (section A), pores with different size show different responses to the external stress, as shown in Figure 2. Form the microstructure, it is also clear that the shape of both the intrinsic and extrinsic pores changes to an ellipsoidal shape when the sample is sinter-forged (as was assumed in Section 3). The major axis of the small intrinsic pores (average pore size $<2 \mu \mathrm{m}$ ) tend to align parallel to the loading direction (Figure 2 (a)), in contrast to large pores or extrinsic pores (average pore size $>2$ $\mu \mathrm{m})$ for which the major axis aligns perpendicular to the loading direction (Figure 2 (b)). 


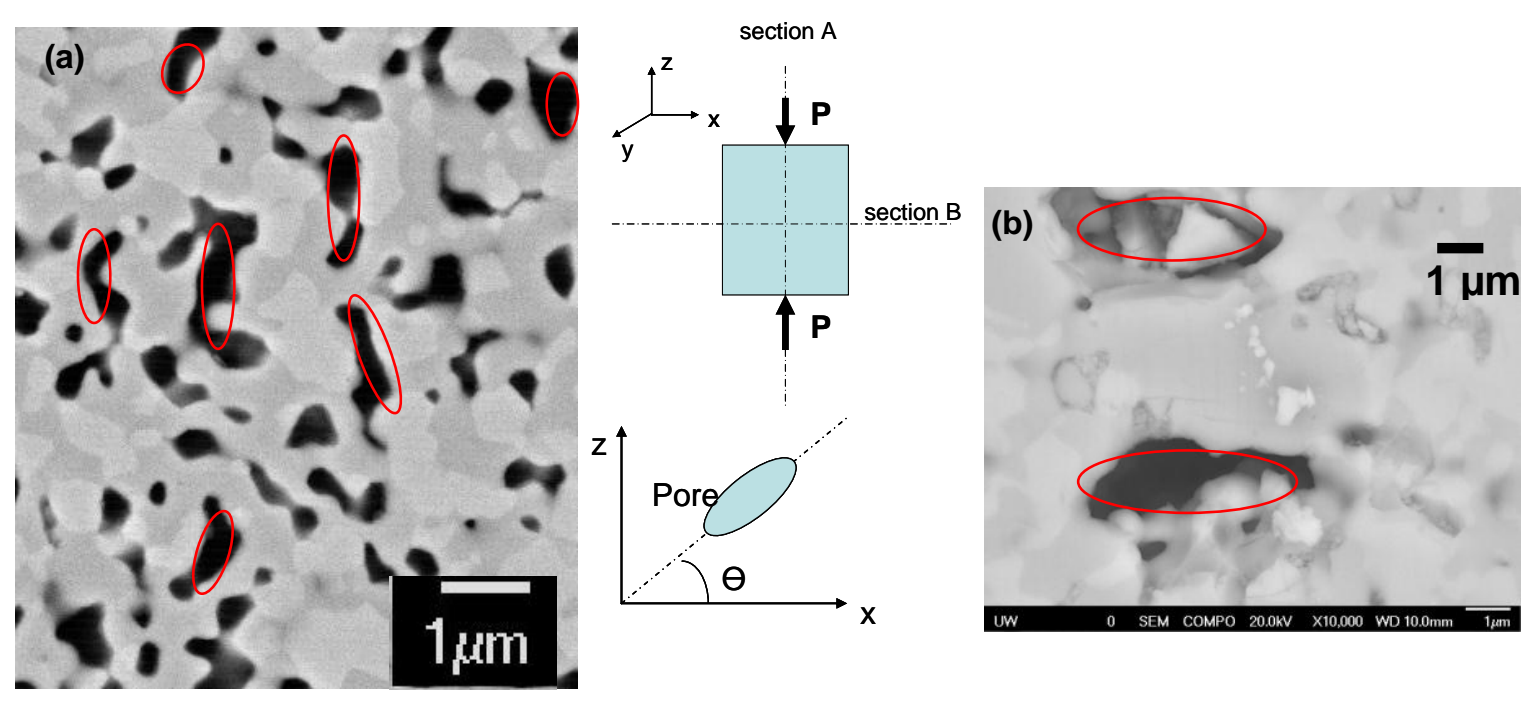

Fig. 2: Microstructures of (a) Intrinsic pores in sample with 0\% PMMA and (b)

extrinsic pores in sample with $30 \%$ PMMA, Sinter-forged at $1300^{\circ} \mathrm{C} 1573 \mathrm{~K}$, under 5

$M P a$.

To qualtify quantify this phenomenon, the distribution of pore angles for intrinsic and extrinsic pores sinter-forged at $1573 \mathrm{~K}$ under a uniaxial stress of $5 \mathrm{MPa}$ was measured and plotted in a polar orientation map, as shown in Figures 3 (a) and (b). For intrinsic pores as shown in Figure 3 (a), most of pores are oriented at angles between 60 to 120 degree, and for extrinsic pores, most of them are distributed in $0-30$ or $150-180$ degree range. These results validate and quantify our observation of differnet nature effect of applied stress on ef the orientation of the intrinsic and extrinsic pores shown in Figure 2. 

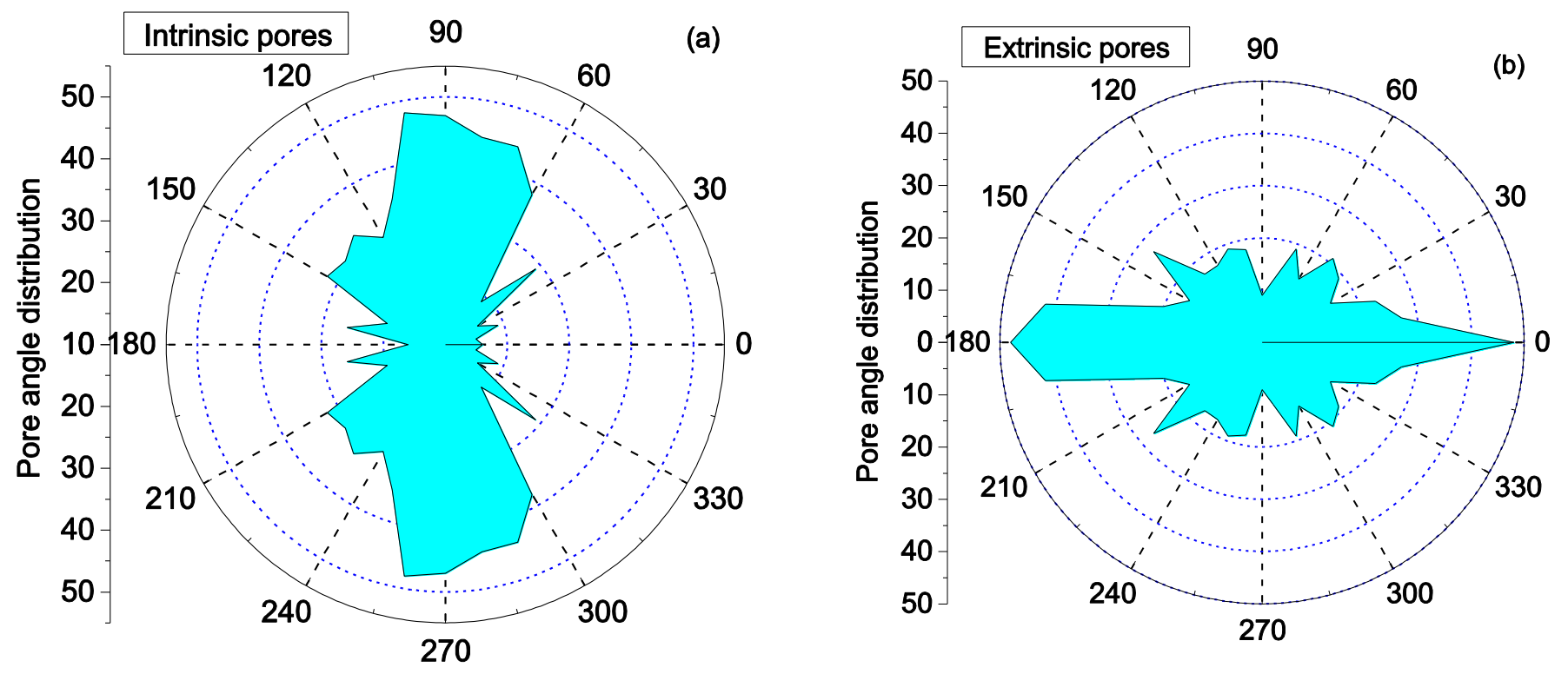

Fig.3: Pore angle distribution of (a) intrinsic pores in composite cathode with 0\% PMMA and (b) extrinsic pores in composite cathode with $30 \%$ PMMA, sinter-forged at $1300^{\circ} \mathrm{C}$ $1573 \mathrm{~K}$ under uniaxial compressive stress of $5 \mathrm{MPa}$

\subsubsection{Effect of uniaxial stress on pore orientation}

Intrinsic and extrinsic pores showed different response to external stress in terms of their orientation relative to the loading axis. The effect of the level of the applied stress on the pore orientation was also investigated. Figure 4 shows microstructures of samples sintered at temperature of $1523 \mathrm{~K} 1250^{\circ} \mathrm{C}$ with uniaxial stress ranging from 3 to $12 \mathrm{MPa}$. Clearly, the pressure applied during sintering affected the microstructures by changing pore amount, pore size and pore orientation. Note the pore volume fraction decreases with increase of pressure. This is consistent with the changes in porosity with stress (Fig. 1). Examination of the anisotropic shape for extrinsic pores has shown that extrinsic pores were slightly elongated at $3 \mathrm{MPa}$, and became further elongated at $5 \mathrm{MPa}$. However, 
the elongation factor decreases with continued increase of pressure above $5 \mathrm{MPa}$, indicating a decrease in anisotropy.
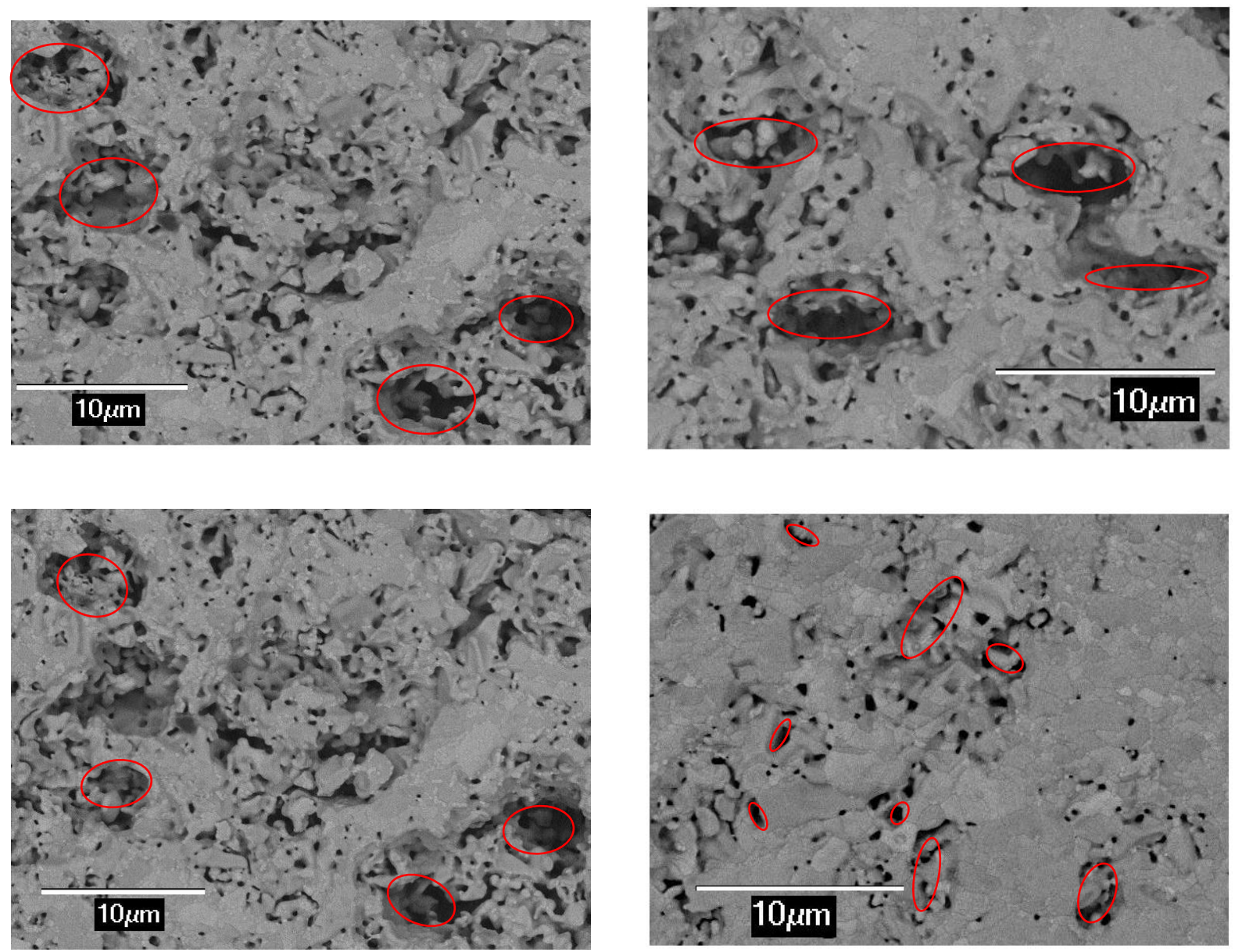

Fig. 4 Extrinsic pore shape evolution as a function of uniaxial stress during sinter forging at (a) $3 \mathrm{MPa}$,(b) $5 \mathrm{MPa}$, (c) $9 \mathrm{MPa}$ and (d) $12 \mathrm{MPa}$. All samples were sinter-forged at $1250^{\circ} \mathrm{C}$

\section{$1523 \mathrm{~K}$ and had $30 \%$ PMMA pore former}

In order to quantify the orientation of extrinsic pores at different stress levels, the distribution of pore angle for microstructures of cathode with 30\% PMMA was plotted in a polar polar distribution map as shown in Figures 5 (a) to (d) for different stress levels. Form these plots it can be seen that the highest degree of the preferred orientation for extrinsic pores (perpendicular to the loading axis) is for samples sinter-forged at an 
intermediate stress of $5 \mathrm{MPa}$. For stress higher than $5 \mathrm{MPa}$, the extent of preferred pore orientation decreases. This quantifies the qualitative observation made from the micrographs in Figure 4. 

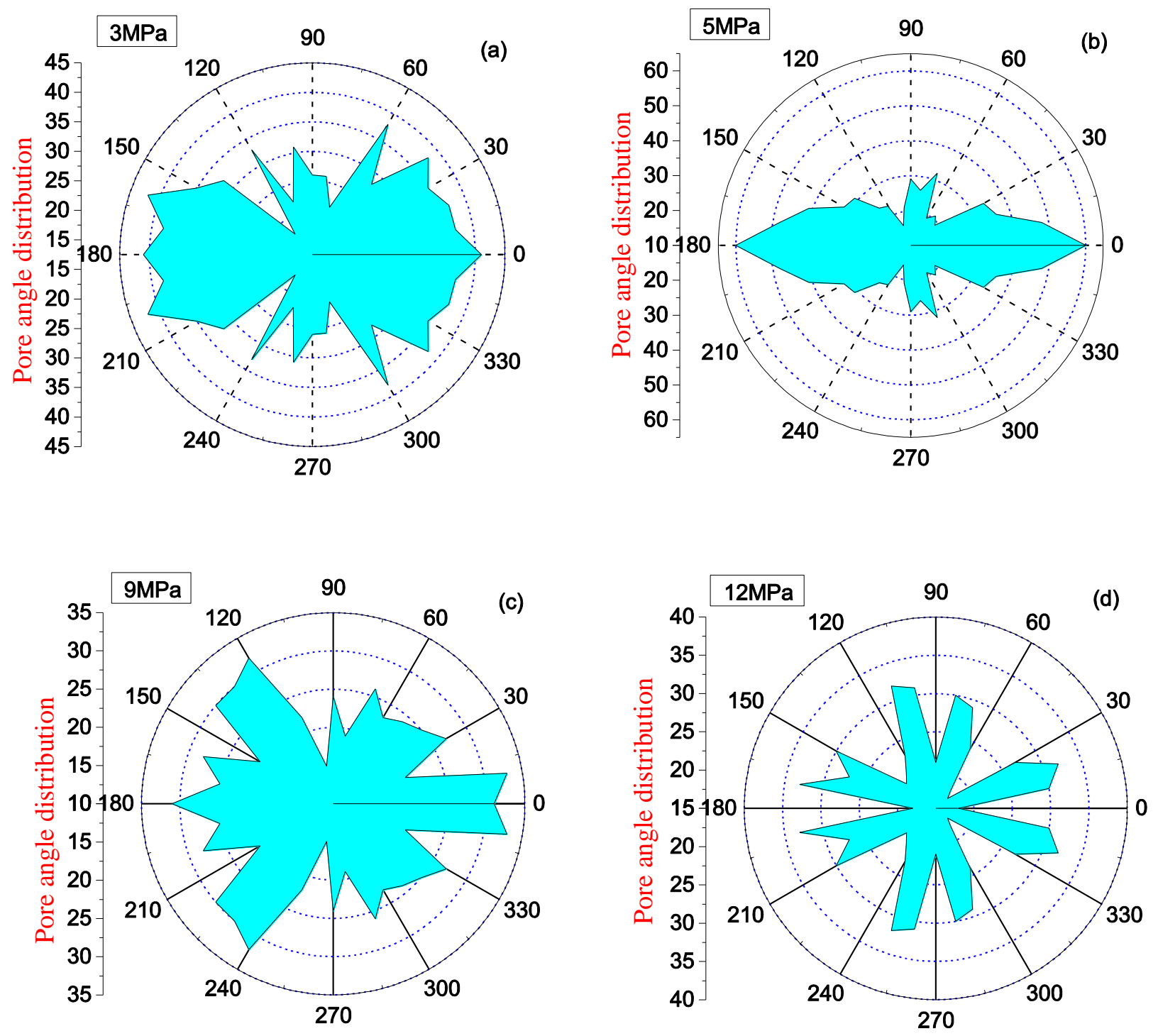

Fig. 5: Distribution of pore orientation angle for extrinsic pores in samples with $30 \%$ PMMA sinter-forged at $1250^{\circ} \mathrm{C} 1523 \mathrm{~K}$ under different pressures. 400-600 pores were analyzed for each sample. 
The distribution of intrinsic pore orientation angle as a function of applied stress is shown in the polar plots in Figure 6. In this case, samples without PMMA were sinter-forged at $1250^{\circ} \mathrm{C} 1523 \mathrm{~K}$ under a uniaxial stress between $3 \mathrm{MPa}$ to $12 \mathrm{MPa}$ (same conditions as those for samples with pore formers (Figure 5)). As shown in Figure 6, the preferred orientation of intrinsic pores (parallel to the applied stress) decreases with increase of uniaxial stress beyond $3 \mathrm{MPa}$.
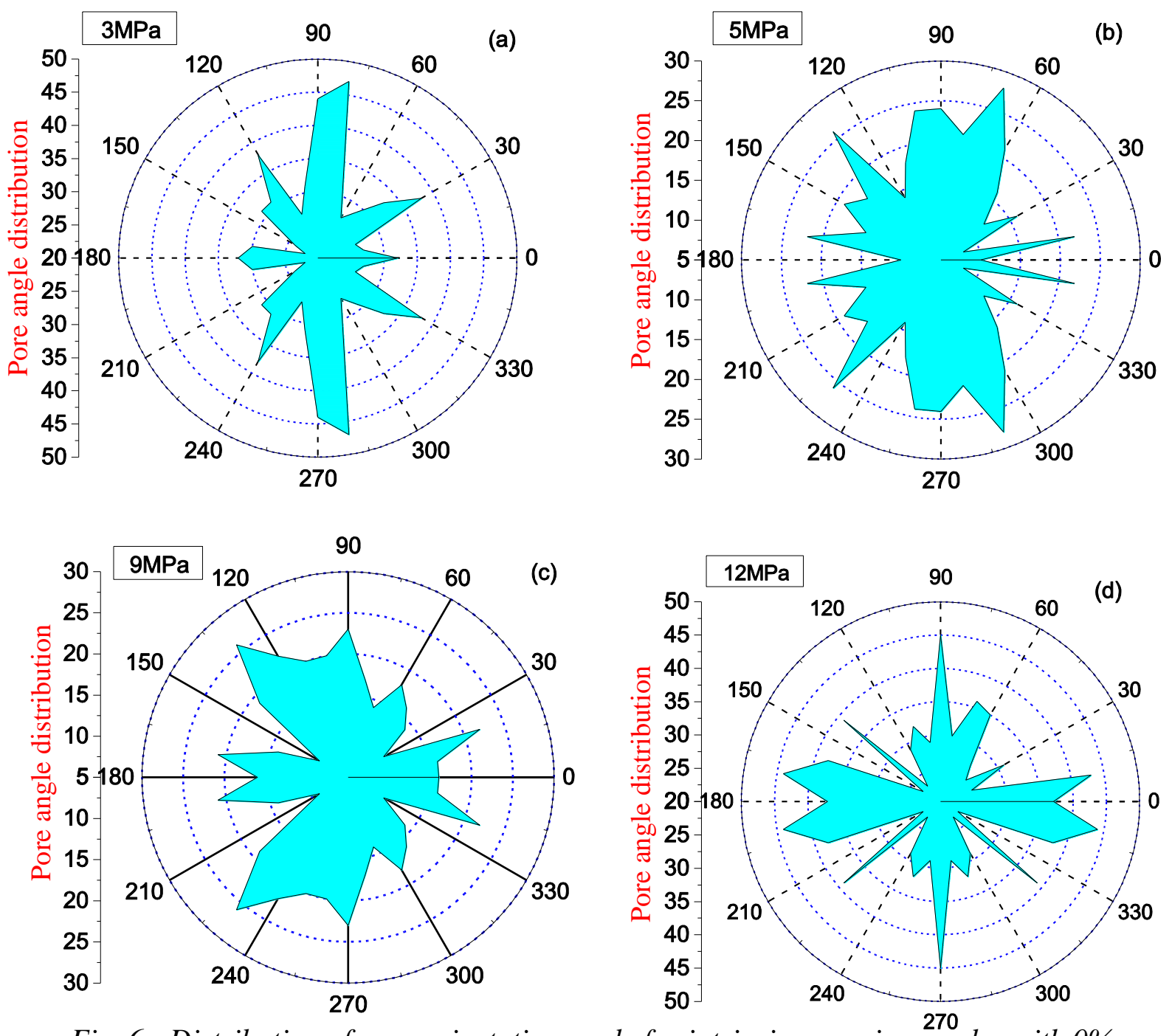

Fig. 6: Distribution of pore orientation angle for intrinsic pores in samples with $0 \%$

PMMA sinter-forged at $1250^{\circ} \mathrm{C} 1523 \mathrm{~K}$ under different pressures. 400-600 pores were analyzed for each sample. 
The complete evolution of the anisotropy as a function of applied stress can be quantified for both intrinsic and extrinsic pores. The results for average pore angle, average pore size, pore orientation index, and pore elongation rate is shown in Figure 7 as a function of applied uniaxial stress. These parameters are defined in Section 3 in equations 1-3. With the stress of $0,3,5,9$ and $12 \mathrm{MPa}$, the porosity for samples with 0\%PMMA is $30.7 \%, 22.1 \%, 18.2 \%, 16.3 \%$ and $15.1 \%$, respectively. Correspondingly, for samples with 30\% PMMA, porosity is $44.3 \%, 35.6 \%, 29.4 \%, 28.2 \%$ and $25.1 \%$.
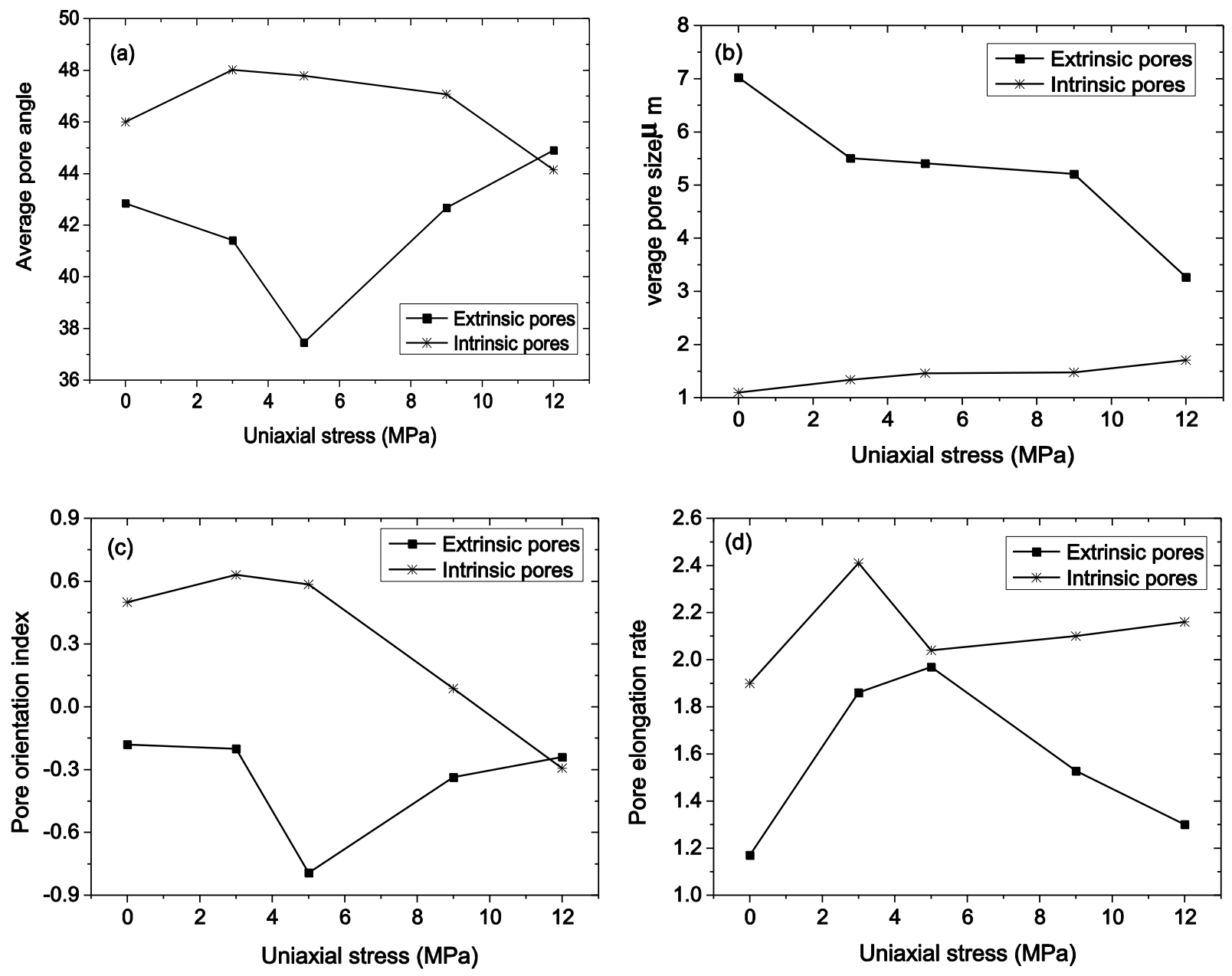

Fig.7: Quantification of the anisotropy of intrinsic and extrinsic pores as a function of uniaxial stress: (a) average pore angle (b) average pore size (c) pore orientation index (d) pore elongation rate. All samples sinter-forged at $1250^{\circ} \mathrm{C} 1523 \mathrm{~K}$ 
Fig. 7 (a) indicates that for extrinsic pores, the tendency to preferentially align increases up to $5 \mathrm{MPa}$ and then decreases. This trend is consistent with change of pore orientation index (Fig. 7 (c)) and pore elongation factor (Fig.7 (d)). All these parameters show that anisotropy of extrinsic pores peaks at $5 \mathrm{MPa}$, and then decreases as sinter-forging stress increases. The average pore size of the extrinsic pores decreases as the stress increases (Fig. 7 (b)).

For intrinsic pores, two conclusions can be drawn from the Fig. 7. (i) Anisotropy reaches peak at $3 \mathrm{MPa}$ then decreased. This is reflected in the results for the average pore angle (Fig. 7 (a)), pore orientation index (Fig. 7 (c)) and pore elongation factor (Fig. 7 (d)); (ii) average pore size increases with increase of pressure (Fig. 7 (b)). This last observation is expected since the smaller intrinsic pores either are eliminated earlier in sintering or coarsen as densification and grain size increases, which also lead to a decrease in the ratio of the intrinsic pores to the extrinsic pores. Note that the samples sinter forged at higher stress would have higher density. The pore orientation index (Fig. 7 (d)) is negative for all values of the stress for intrinsic pores (pore align parallel to the stress axis). It is positive for all values of stress except $12 \mathrm{MPa}$ for the extrinsic pores (pore alignment perpendicular to the stress axis). With At high stress level, the extrinsic pore size becomes small and starts to approach the intrinsic pore size (Fig. 7 (b)) and this may explain the observation of the negative pore orientation index for extrinsic pores at these high stresses.

Overall the effects of applied stress on the porous microstructure, presented here, are the first observations and their understanding needs further investigation. An intriguing 
observation, which requires further confirmation and analysis, is the maximum in the anisotropy at intermediate stress levels for both intrinsic and extrinsic pores.

\subsection{Effect of stress on grain growth}

Sintering processes are always accompanied by grain growth, because the capillary driving forces for sintering (involving surfaces) and grain growth (involving grain boundaries) are comparable in magnitude, both being proportional to the reciprocal grain size. In free sintering, the density has been found to be the parameter that controls grain size. Thus grain size vs. density curves superimpose for samples sintered at different temperature. However, in sinter forging, applying external stress can change the grain growth vs. density trajectory and hence the resultant microstructure of the ceramics. For example, microstructures of samples in Figure 8 (a) and 8 (b) have almost the same relative density of $77 \%$, but obviously different average grain sizes: $22 \%$ decrease in average grain size is found for samples sintered under $12 \mathrm{MPa}$ of uniaxial stress. Note that the two samples were held at the isothermal temperature for the same time and in order to get the same density, the temperature of the sinter-forged sample was lower. Also, note that these high magnification micrographs are from regions of the sample where there are no extrinsic pores. 

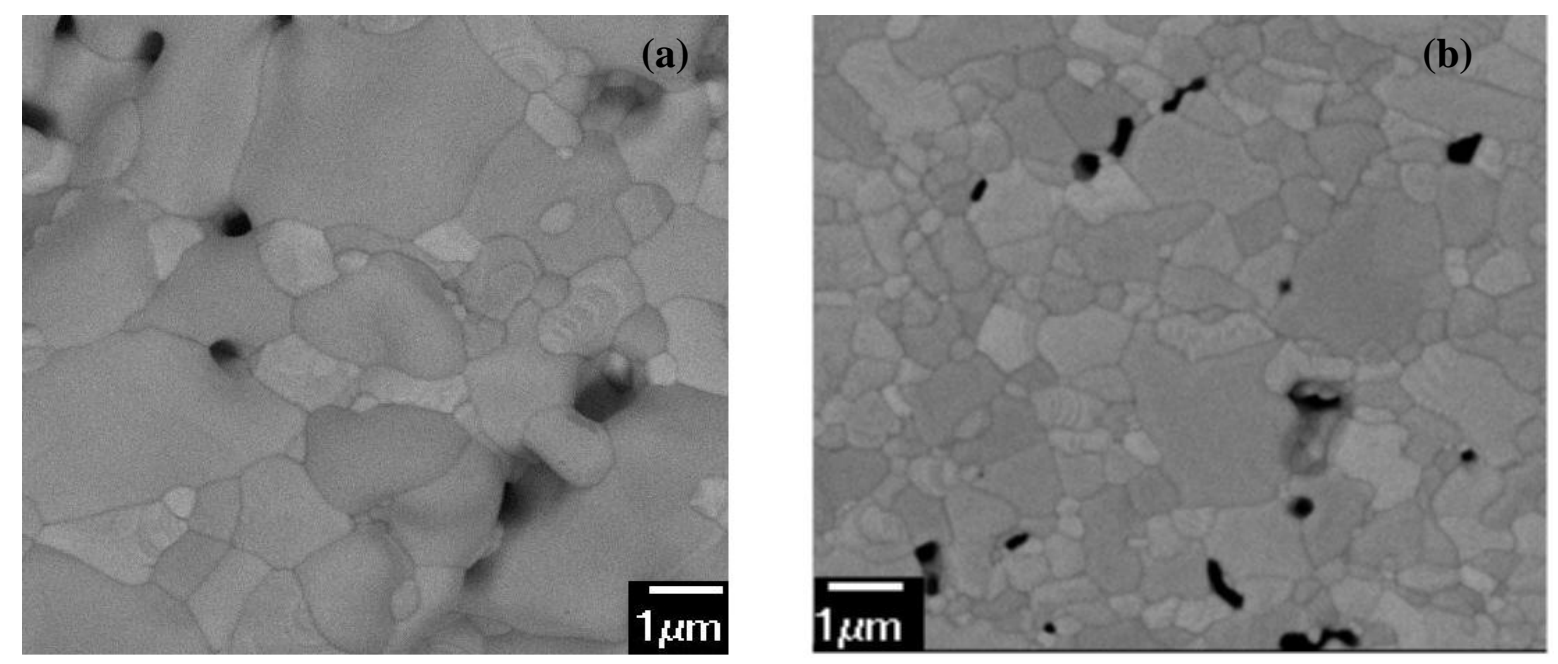

Fig.8: Microstructures of composite cathodes with 30\% PMMA with same relative density of 77\%: (a) free sintered at $-1400^{\ominus} \mathrm{C} 1673 \mathrm{~K}$, (b) sintered at $1250^{\circ} \mathrm{C} 1523 \mathrm{~K}$ with $12 \mathrm{MPa}$ pressure

The effect of uniaxial stress on the grain size vs. relative density trajectories is shown in Figure 9. As can be seen, at the same relative density, a free-sintered sample always has larger grain size than sinter-forged samples. This observation is related to the difference in the time or the temperature required to reach the same density during free sintering and sinter-forging: free sintering needs longer time (and/or higher temperature) and, therefore, manifests more pronounced grain growth. Note as stress increases to $12 \mathrm{MPa}$, the grain size of cathodes with/without pore former begins to decrease. These observations are similar to the well-documented effect of stresses on grain size during hot pressing. This could be due to dynamic grain growth controlled by the level of externally applied stresses [35 37]. These results suggest a possibility of densification without grain growth: applying external stress suppresses the grain-boundary migration while keeping grainboundary diffusion active. These results indicate that if the sample is sinter-forged under 
high enough stress, then it maybe possible to completely suppress grain growth. Another important point to note in Figure 9 is that the density at which rapid grain growth starts for the stress free sintered sample is different for the samples with and without pore formers. This indicates that the extrinsic pores have little effect on grain size. Rapid grain growth starts when the grain/intrinsic pore system reaches a particular density. If extrinsic pores are also present, this happens at a lower overall density. Also, note that due to the small grain growth rates in the sinter-forged samples, there is almost no difference in the grain size vs. density trajectory for the sinter forged samples with or without pore formers.

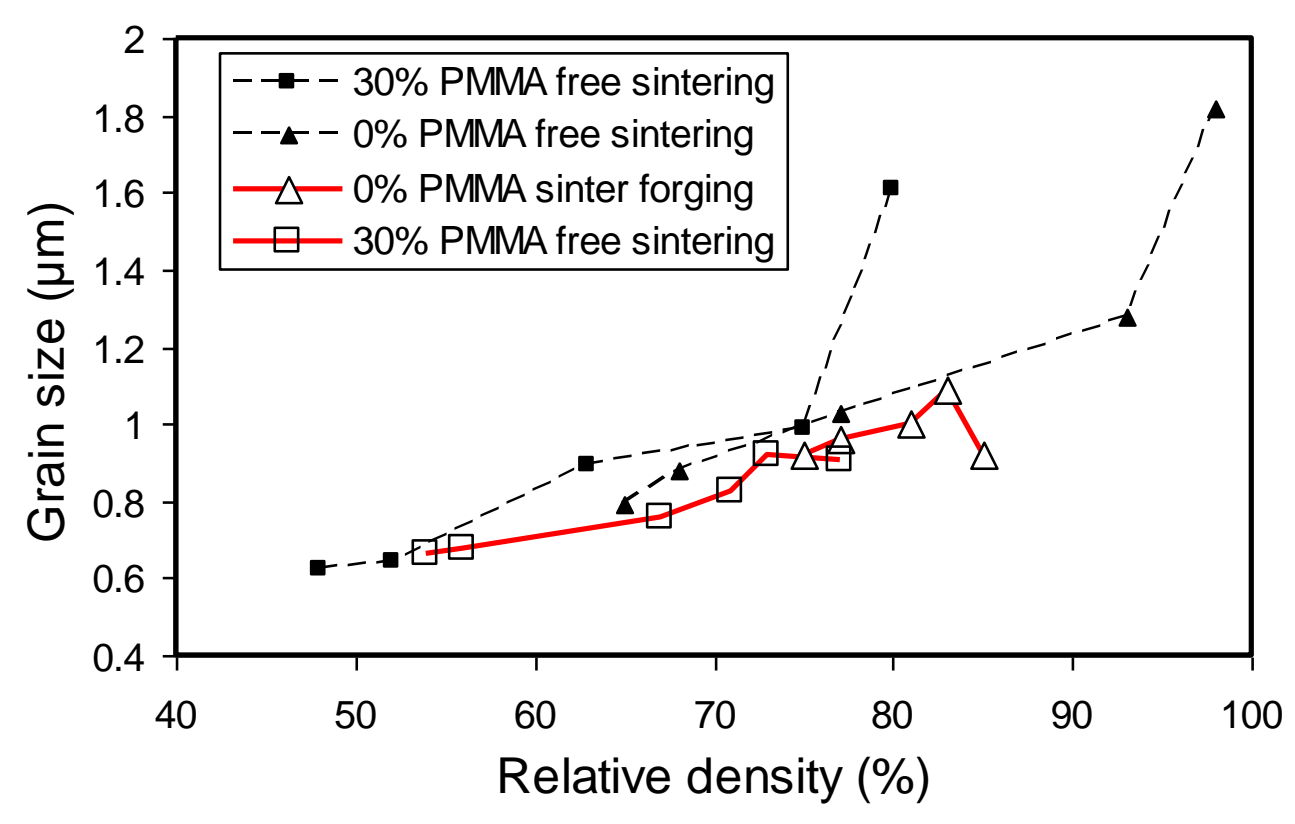

Fig.9 Grain size vs. density for samples with and without pore formers. Results for both stress-free sintered and sinter forged samples (at $12 \mathrm{MPa}$ ) 


\subsection{Densification kinetics}

The densification kinetics were quantified by measuring the densification rates in isothermal stages, and comparing them with the prediction based on Coble's model for boundary diffusion controlled densification [36-38]. The normalized densification rate $\left(\frac{1}{\rho} \frac{d \rho}{d t}\right.$, where $\rho$ is relative density and $t$ is time) is given by:

$$
\frac{1}{\rho} \frac{d \rho}{d t}=(16 \sigma / \Omega / k T)\left(\delta D / l^{3}\right)
$$

In Eq. $4, \gamma$ is the surface energy, $\Omega$ is the atomic volume, $k$ is constant, $T$ is temperature, $l$ is grain size, $D$ is the boundary diffusion coefficient, and $\delta$ the grain boundary thickness. Effective stress $\sigma$ was calculated from applied stress $\sigma_{a}$ and porosity P:

$$
\sigma=\sigma_{a}(1+2 P)
$$

In Eq. $4, \sigma \gamma \Omega / k T$ may be viewed as the normalized driving force, and $\delta D / l^{3}$ is the standard kinetic factor that enters the strain-rate equation for grain-boundary diffusion controlled processes such as sintering, diffusional creep. The densification rate can be obtained from density-time plots. Figure 10 shows the normalized sintering rates against density for samples with and without pore former sintered and sinter-forged (under different stresses) at $1250 \mathrm{C} 1523 \mathrm{~K}$. 


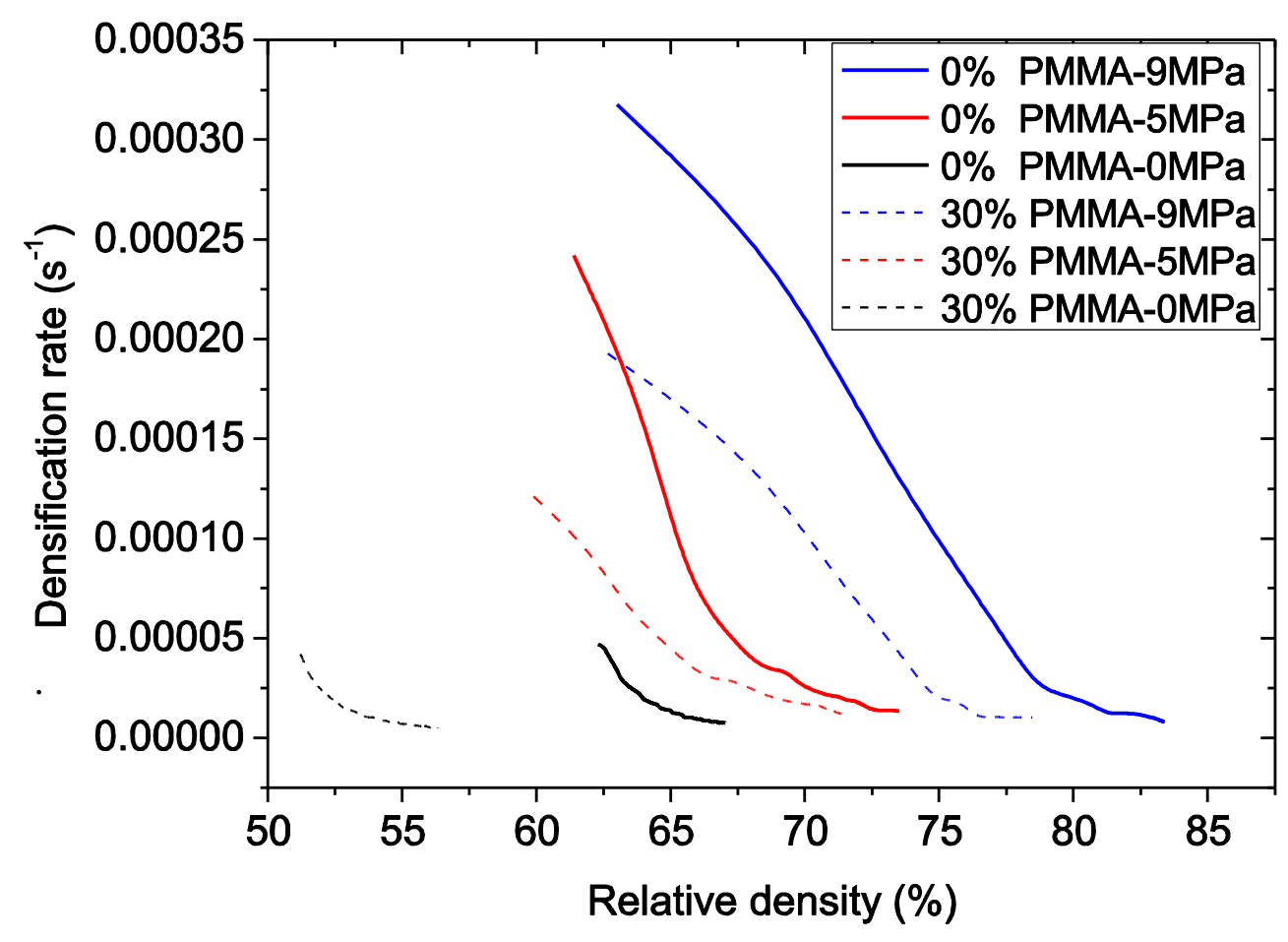

Fig. 10: Densification rate as a function of density for samples with and without pore formers. Results for both stress-free sintered and sinter forged samples at $1250 \mathrm{C} 1523$ $\mathrm{K}$.

It is clear from Figure 10 that use of stress during sintering accelerates densification for all samples as expected from Eq. (4) (by comparing the densification rate at the same density for stress free sintered and sinter-forged samples). The densification rate, at a given density, increases with increasing stress level. Another interesting observation is that the curves for samples with and without pore formers are almost parallel to each other and sifted along the density scale. This implies that densification is primarily controlled by the intrinsic pores and the extrinsic pores just shrink by an amount proportional to the overall shrinkage. As expected, the normalized sintering rate decreases as density increases (e.g. by a factor of 10 as the density increases from $60 \%$ to 
84\%). This decrease is primarily due to the increase in the diffusion distance associate with grain growth

For samples with pore formers, some deviations from the trends predicted by the pure diffusion based model can be attributed to the partial filling of the large pores through viscous flow as discussed in the next section.

\section{DISCUSSIONS Discussions}

A possible explanation of the evolution of the intrinsic pore shapes in free sintering and in sinter forging is schematically illustrated in Fig. 11. Considering a two dimensional situation with four particles in a sample, the extent of neck growth at the position A and B for a sample freely sintered is the same, however, when the sample is compressed with uniaxial stress, the applied stress leads to a faster growth of neck A. Similar situation happens when the ceramic is sintered in a constrained geometry. This difference in neck growth causes the orientation of the pores to develop in the direction parallel to the loading direction (or perpendicular to the direction of the constraint). Thus, during sinter forging, the intrinsic pores are expected to become anisotropic and orient their long axis along the direction of the compressive stress.

For extrinsic pores, the shape flattening in the direction perpendicular to the direction of the applied stress, by and large, replicates the results observed by Kellett and Lange [ 37 39]. They observed that large size pores, maintained a uniform width normal to the applied load while their height in the direction of the applied load decreased. The contact between the top and bottom of the pore eventually leads to pore disappearance. 


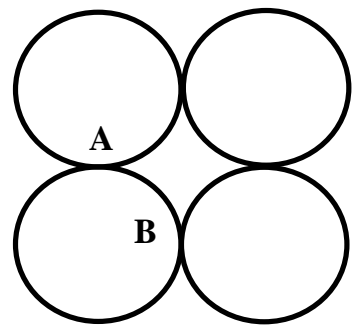

Green state

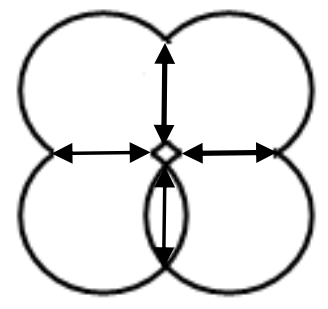

Free sintering

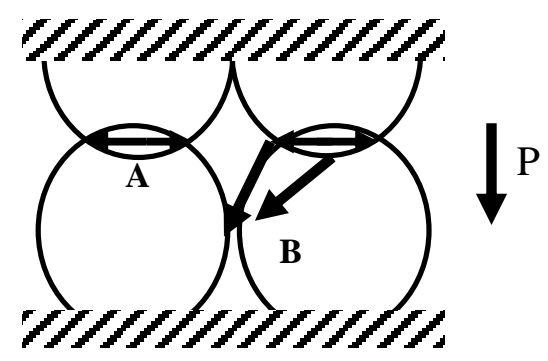

Constrained/ loaded sintering

Fig. 11: Schematic to illustrate the differences in the evolution of intrinsic pores during free sintering vs. sinter-forging or constrained sintering

During sinter forging, two driving forces control the pore size and shape evolution. External stress is dominant for large extrinsic pores, and capillary stress is dominant for small intrinsic pores since the capillary stress is inversely proportional to the pore size and therefore increases as the pore size decreases. Using intrinsic pores sintered with 3 MPa as an example (Fig. 6), the viscous deformation induced by capillary stress is higher than the viscous deformation induced by the external stress, therefore pores orient parallel to the loading direction. As pore size increases to a critical size, the effect of external stress becomes lager than the effect of diffusion in controlling pore orientation, a small amount of pores orient perpendicular to the applied compressive stress.

This analysis can approximately explain the shape evolution of the large size pores, however, for small size pores, additional insight at the particle length scale is needed. Indeed, the capillary stresses act in both parallel and perpendicular to the applied load directions, and should result in the same local pore shrinkage rates in both directions. 
Therefore, the addition of the load in the direction parallel to the applied stress should not cause the pore flattening in the same direction.

In this connection, to explain the difference in the behavior of large and small size pores we suggest a concept of the combined diffusional-viscous mass transfer mechanism is proposed. The viscous flow is driven by stress gradients as opposed to the diffusional flow, which is driven by concentration gradients. It is logical to assume different pore filling mechanisms for large and small pores during sinter forging leading to the divergence in the pore shape evolution for pores of different size. Extrinsic large pores with sizes much larger than the grain size should deform like pores in a linear viscous material. The filling of the large pores may include the introduction of whole particles/grains or blocks of grains into the pore volume. At the same time, small pores do not offer sufficient space for this kind of mass transfer. They can be filled by the combination of diffusion fluxes and particle sliding. Their shape change is governed by the directions of the maximum diffusion fluxes that are formed in planes normal to the loading. As a result, large pores are squeezed in the loading direction but small pores are squeezed predominantly in the direction normal to the loading.

For extrinsic pores, as pores shrink during sintering as pressure increases, the strain effect on the pores will be reduced, as well as the anisotropy. At pressure of $12 \mathrm{MPa}$, the average pore size decreases to $2.8 \mu \mathrm{m}$ from original $7.1 \mu \mathrm{m}$ at $0 \mathrm{MPa}$, which is close to intrinsic pore size range $(0-2 \mu \mathrm{m})$. Therefore it is not a surprise why anisotropy decrease after $5 \mathrm{MPa}$ and elongated pores become more spheroidized with higher pressures, as shown in Figures 4, 5 and 7. 
Since anisotropy in sinter forging and constrained sintering is related to pore size, we expect that there is a critical pore size where the effect of anisotropic strain or stress becomes equal to the effect of diffusion. Pores larger than this critical size will orient perpendicular while those smaller than this will orient parallel to the applied compressive stress. A thorough understanding of this critical pore size together with its dependent on the material and processing parameters is expected to lead to improved understanding of the fundamentals of sintering. In addition, it will lead to a predictable control over the evolution of the anisotropic porous microstructure during sinter forging.

Rigorous confirmation of the above-mentioned qualitative hypothesis requires multi-scale modeling of sintering anisotropy phenomena. The needed theoretical framework and further advancing previously developed concepts [22, 38 40], for understanding the differences between the small and large pore evolution based on the specifics of viscous and diffusional mass transport during sinter-forging processes, is a subject of our ongoing research.

\section{CONCLUSIONS Conclusions}

In this work, we investigated the evolution of pore anisotropy and grain growth in hierarchical porous ceramics during sinter forging. Experimental results show that development and evolution of anisotropy in the pore shape depends on pore size and sinter forging conditions. A clear difference is observed in the preferential orientation of the extrinsic and intrinsic pores. The intrinsic pores preferentially align parallel while the extrinsic pores align perpendicular to the direction of the applied compressive stress. For both extrinsic and intrinsic pores, the extent of anisotropy increases as the stress increases 
for relatively low stresses (3-5MPa), however, as stress continues to increase, the extent of anisotropy decreases. This could be due to the higher density of samples that have been sinter-forged at higher stresses. For the explanation of the difference in the shape change of large size and small size pore a hypothesis of the combined diffusional-viscous mechanism of mass transfer under conditions of sinter forging is proposed. The qualitative theoretical concept requires further multi-scale modeling of sintering anisotropy phenomena. As expected, the grain size of sinter-forged samples is always smaller than stress free-sintered samples (at the same density) and is controlled by only the intrinsic pores. Similarly, the densification rate is primarily controlled by the intrinsic pores and accelerated by applying external compressive stresses.

\section{Acknowledgements}

The support of US National Science Foundation Division of Civil and Mechanical Systems and Manufacturing Innovations for this collaborative DMREF project (NSF Grant nos. CMMI 1502392 and CMMI 1234114) and of Saint-Gobain Ceramics \& Plastics Inc. for this work is gratefully acknowledged. 


\section{References}

[1] Studart AR, Gonzenbach UT, Tervoort E, Gaukler LJ. Processing routes to macroporous ceramics: a review. J Am Ceram Soc 2006;89:1771-89.

[2] Rahaman MN, Brook RJ, DeJonghe LC. Effect of shear-stress on sintering. J Am Ceram Soc 1986;69:53-8.

[3] Rahaman MN, DeJonghe LC, Hsueh $\mathrm{CH}$. Creep during sintering of porous compacts. J Am Ceram Soc 1986;69:58-60.

[4] Venkatachari KR, Raj R. Shear deformation and densification of powder compacts. J Am Ceram Soc 1986;69:499-506.

[5] Garino TJ, Bowen HK. Kinetics of constrained film sintering. J Am Ceram Soc $1990 ; 73: 251-7$

[6] Riedel H, Kozak V, Svoboda J.Densification and creep in the final stage of sintering. Acta Metall1994; 42(9):3093-103.

[7] Kwon YS, Son G, Suh J, Kim KT. Densification and grain growth of porous alumina compacts. J Am Ceram Soc 1994;77:3137-41.

[8] Mohanram A, Lee SH, Messing GL, Green DJ. Constrained sintering of lowtemperature co-fired ceramics. J Am Ceram Soc 2006;89:1923-9.

[9] Bordia RK, Scherer GW. Overview No. 70: on constrained sintering I. Constitutive model for a sintering body. Acta Metall1988; 36(9):2393-7.

[10] Bordia RK, Scherer GW. Overview No. 70: On constrained sintering II. Comparison of constitutive models. Acta Metall1988; 36(9):2399-409.

[11] Bordia RK, Scherer GW. Overview No. 70: On constrained sintering III. Rigid inclusions. Acta Metall1988; 36(9):2411-6. 
[12] Olevsky E, Theory of sintering: From discrete to continuum. Mater Sci \& Eng R 1998; 23: 41-100.

[13] Olevsky E, Tikare V, Garino T. Multi-scale modeling of sintering - A Review. J Am Ceram Soc 2006;89:1914-22.

[14] Green DJ, Guillon O, Rödel J. Constrained sintering: A delicate balance of scales. J Europ Ceram Soc 2008; 28: 1451-66.

[15] Guillon O, Aubach E, Bordia RK, Rödel J. Constrained sintering of alumina thin films: Comparison between experiments and modeling. J Am Ceram Soc 2007;90:1733-7. [16] Zuo R, Aulbach E, Bordia RK, Rödel J. Critical evaluation of hot forging experiments: Case study in alumina. J Am Ceram Soc 2003;86:1099-105.

[17] Wonisch A, Guillon O, Kraft T, Moseler M, Riedel H, Rödel J. Stress-induced anisotropic behaviour of sintering alumina: discrete element modeling and experiments. Acta Mater 2007;55(15): 5187-99.

[18] Ollagnier JB, Guillon O, Rödel J. Effect of anisotropic microstructure on the viscous properties of a LTCCmaterial. J Am Ceram Soc 2007;90:3846-51.

[19] Guillon O, Weiler L, Rödel J. Anisotropic microstructural development during the constrained sintering of dip-coated alumina thin films. J Am Ceram Soc 2007;90:1394400.

[20] Wang X, Atkinson A. Microstructure evolution in thin zirconia films: Experimental observation and modeling. Acta Mater 2011;59(6): 2514-25.

[21] Jagota A, Dawson PR, Jenkins JT. An anisotropic continuum model for the sintering and compaction of powder packings. Mech Mater 1988; 7: 255-69. 
[22] Olevsky EA, Kushnarev B, Maximenko A, Tikare V, Braginsky M. Modeling of anisotropic sintering in crystalline ceramics. Phil Mag 2005;85(19):2123-46.

[23] Ching HN, Pan J. Modeling microstructural evolution of porous polycrystalline materials and a numerical study of anisotropic sintering. J Comput Phys 2005;204: 43061.

[24] Bordia RK, Zuo R, Guillon O, Salamone S M, Rödel J. Anisotropic constitutive laws for sintering bodies. Acta Mater 2006;54: 111-8.

[25] Zavaliangos A, Missiaen JM, Bouvard D. Anisotropy in shrinkage during sintering. Sci Sinter 2006;38(1):13-25.

[26] Wakai F, Bordia RK. Microstructural evolution and anisotropic shrinkage in constrained sintering and sinter forging. J Am Ceram Soc 2012;95:2389-97.

[27] Exner HE, Petzow G, Wellner P. Problems in the extension of sintering theories to real systems. In: Kuczynski GC, editor. Sintering and related phenomena, New York: Springer Publishing LLC; 1972, p.351-62 .

[28] Evans AG, Hsueh CH. Behavior of large pores during sintering and hot isostatic pressing. J Am Ceram Soc 1986;69:44-8.

[29] Slamovich EB, Lange FF. Densification of large pores: I. Experiments. J Am Ceram Soc 1992;75:2498-508.

[30] Oh KS, Kim DY, Cho SJ. Shrinkage of large isolated pores during hot isostatic pressing of presintered alumina ceramics. J Am Ceram Soc 1995;78:2537-40.

[31] Flinn BD, Bordia RK, Rödel J. Evolution of strength determining flaws during Sintering. In: German RM, Messing GL, Cornwall RG, editors. Sintering Technology, New York: Marcel Dekker Inc;1992, p. 13-20. 
[32] Flinn BD, Bordia RK, Zimmerman A, Rödel J. Evolution of defect size and strength of porous alumina during sintering. J Europ Ceram Soc 2000; 20: 2561-8.

[33] Wilson JR, Cronin JS, Duong AT, Rukes S, Chen H-Y, Thornton K. Effect of composition of ( $\mathrm{La} 0.8 \mathrm{Sr} 0.2 \mathrm{MnO} 3-\mathrm{Y} 2 \mathrm{O} 3$-stabilized $\mathrm{ZrO} 2)$ cathodes: Correlating threedimensional microstructure and polarization resistance, J Power Sourc 2010; 195: 182940

[34] Mendelson MI. Average grain size in polycrystalline ceramics. J Am Ceram Soc 1969;52: 443-8.

[35] Pan J, Ching HN, Cocks ACF. Sintering kinetics of large pores. Mech Mater 2004; 37: 705 .

[36] Haixia Shang, Aravind M, Bordia, RK. Densification and microstructural evolution of hierarchical porous ceramics during sintering. J Am Ceram Soc 2015;98:3424-30.

[37] Hague DC, Mayo MJ. Sinter-forging of nanocrystalline zirconia: II, Simulation. J Am Ceram Soc 1999;82:545-55.

[38] Coble RL. Diffusion models for hot pressing with surface energy and pressure effects as driving forces. J Appl Phys 1970; 41: 4798-807.

[39] Kellett BJ, Lange FF. Experiments on pore closure during hot isostatic pressing and forging. J Am Ceram Soc 1988;71:7-12.

[40] Maximenko AL, Grigoryev EG, Olevsky EA. Homogenization of bi-porous agglomerated powder structures during sintering and pressing. J Am Ceram Soc 2015;98:3445-52. 